\title{
CLINICAL SOCIOLOGISTS: COMING OUT OF THE CLOSET
}

\author{
L. Alex Swan \\ Texas Southern University
}

For several years, many sociologists have been practitioners in personal development and social change. They have worked in various clinics, mental health centers, juvenile delinquency and crime prevention programs, drug addiction programs, suicide prevention centers, and family growth and development programs, applying sociological thinking and knowledge. Moreover, many sociologists have developed therapeutic skills, methods, interactive strategies of intervention, and techniques, and have been involved in applying sociological knowledge and methods to solving mental health, community development, organizational change, and family relations problems. Consequently, there is evidence that sociologists have practiced the application of sociological knowledge in clinical settings.

Now that there is an organized attempt to establish the field of clinical sociology, ${ }^{1}$ there are two objectives that must be satisfied in the process. The first is to unify the scientific and professional aspects of Clinical Sociology so that academicians and practitioners who are committed to clinical research and clinical practice might work to bring these aspects more closely together. The potential rifts among colleagues whose primary commitment is to clinical research, teaching, or practice might be averted were unification achieved.

The second is to provide a comprehensive overview of the field of clinical sociology, detailing the context for clinical diagnosis and treatment, the theoretical foundations for intervention, and the methods and techniques appropriate to group, community, and organizational change. In the process, those issues that are controversial and potentially controversial should be treated. 


\section{CLINICAL SOCIOLOGY DEFINED}

Clinical sociology may be defined as that branch of Sociology dealing with the search for and the application of sociological knowledge, principles and analysis aimed at understanding the group, community, organization and individuals within these units for the purpose of reducing distress, managing conflicts and assisting in achieving meaningful and effective functioning. It is important to the growth and effectiveness of the field that the scientific and the professional aspects be given equal weight in such a definition. This should be especially kept in mind as graduate programs are developed to train clinical sociologists. The research orientation in the curriculum will encourage an inquiring attitude that leads to questions that allow for evaluating new clinical techniques and acquiring additional knowledge. At a point in the development of the field of clinical sociology when new innovative approaches abound, it is especially important for the clinical sociologist to be concerned with scientific evidence. Any other approach would find clinical sociologists being swept along from one fad to the next.

\section{WHAT CLINICAL SOCIOLOGISTS DO}

The activities of clinical sociologists today are broader than those identified by Louis Wirth in his classic article of 1931. During the period captured in his paper, there were several clinics in the United States "in which, in addition to the usual psychiatrists, psychologists, and social workers, the staff included sociologists as well." Clinical sociologists were then limited to practice at these sociological clinics as part of an interdisciplinary team dealing with behavior problems of children. If the defining concern of clinical sociologists is the application of sociological knowledge to the problems of individuals within the context of human interaction systems, then clinical sociologists have been working in a variety of settings including: (1) university sociology and social work departments as teachers and researchers; (2) psychiatric hospitals or outpatient clinics performing research and providing clinical services; (3) community health centers; (4) university student health centers; (5) child guidance centers; (6) private practice as individuals or in group practice; (7) public and private elementary and high schools; (8) state youth authority agencies; (9) juvenile institutions; (10) in prisons; (11) in medical schools; (12) in courts; (13) with attorneys; (14) in probation and parole departments; (15) in industry, as industrial management consultants; (16) and in churches, as family therapists. In all of these settings and roles, clinical sociologists have interpreted data obtained through various research techniques and approaches for the purpose of assisting their clients alleviate problems that inhibit growth and development, optimal activity and positive change.

\section{PROBLEMS AND CLINICAL SERVICES}

Problems with which clinical sociologists may be confronted are: marital problems; those arising from delinquency, crime, drug addiction, alcoholism, school and job adjustment; retirement and other difficulties of the elderly; premarital problems; problems and adjustments in industry, organizations and other such systematic settings.

Clinical services clinical sociologists might provide are: interviewing to assess or diagnose the social situation and the disposition and attitudes involved; counseling and sociotherapy with couples, families, groups, individuals; research into various aspects of human growth, development and family functioning, and modes of treatment; participation in selection, training and supervising of para-professionals as aides in various programs; consultation with community agencies to develop and establish programs to serve the community; and participation in observation and analysis of social situations that provide the context for various problems and conflicts with other social and behavioral clincians. In order to describe and analyze the social situation and the resulting behavior, the clinical sociologist is interested in systematically and scientifically observing and measuring the situation and the behavior so as to make accurate assessments and offer appropriate prescriptions. 
It is important to realize that decisions made and conclusions drawn resulting from these techniques are not always valid and reliable because they are derived from subjective impressions based on the experienced judgment and intuitive skills of practitioners.

\section{CLINICAL METHODS USED BY CLINICAL SOCIOLOGISTS}

Sociologist clinicians use various methods to arrive at their clinical judgments. The case history method, in which clinicians ask questions about the history of the complaint and about the social situation before and during the disorder, is popular. Some clinicians typically interview other significant persons, such as friends, relatives, and even employers, who can supply additional information regarding the life history of the client.

Some clinicians interact freely, without asking any formal questions, in hopes of obtaining data from the unstructured interview transaction. The focus of the attention of the clinicians is on the here-and-now situation of the clients and not on the past. Usually, attention is given to the non-verbal as well as verbal communication patterns of the clients. In the process, diagnosis and treatment take place.

Other clinicians rely heavily on formal testing for the purpose of diagnosis. Because these tests are standardized, they are perceived to be reliable and valid. There has been much debate, however, about the objectivity of such scoring systems. Psychologists and psychiatrists, and in some cases social workers, are the primary clinicians who have relied on testing to understand, describe and evaluate the personalities, attitudes and dispositions of clients. In the process of analysis of the test data, the intuitive skills and judgments of the clinician are combined with the data to provide a more complete analysis. Clinical sociologists have not yet taken a position on the clinical value of such tests; some have found tests only partly useful because of their structural and content limitations. If other clinicians do not point out their limitations in diagnosis and treatment, clinical sociologists, because of their historical disassociation from testing, especially psychological testing, can assume this role when working with a team of clinicians.

Systematic observation is another method of collecting data for diagnosis and treatment. In a clinical setting, the clinical sociologist can rely on observation of the individual family or group behavior to gather data that could not be obtained any other way. If the therapist wants to evaluate the non-verbal and verbal communications of the family members within the context of family functioning, it is appropriate to observe either as a participant-observer or an observer-participant. The therapist should then be alert to notice individuals' interpretations of each other's communications, the discrepancies in communications, and the sharing of concepts and meanings in the process of communication. Every form of interaction, and the interpretations and meanings associated with interaction, will come under the close scrutiny of the clinical sociologist. If children are having difficulty interacting with classmates, the clinical sociologist might observe the children in the social setting of the school environment for purposes of diagnosis and treatment. In each clinical situation the therapist will determine what is important either before or during observation. In fact, the social situation in which the individual functions is a most important context for systematic observation. The social situation, therefore, is the laboratory in which to obtain data for understanding the nature and extent of problems faced by the individual, family, or group. Distortion and a one-sided view of human behavior are possible when people are studied in artificial settings, rather than the natural habitat of the particular behavior under consideration.

Whenever possible, the clinical sociologist, as a family therapist, should make occasional or regular visits to the home, where the family members can be viewed in their natural everyday roles and relationships to one another.

\section{ROLE BEHAVIOR OF CLINICIANS AND CLIENTS}

In the role of practitioner, clinical sociologists perform tasks that border on research. Consequently, effective functioning in 
clinical practice is enhanced by clinical research that helps to formulate explanations (theory) about the behavior of clients and to apply the resulting knowledge. Problem solving is enhanced by the results of research and the experiences of clinicians with clients. The research and theory posture of the clinician is important in successfully helping clients understand their problems and how they might handle them. This posture is best whether the clinician is dealing with troublesome spots, conflicts or crises.

The role of the clinical sociologist is to assist clients (individuals, groups, families, organizations, etc.) to fully understand the dynamics of their social situation, those aspects of their interaction and relationships that impede growth and development, and those patterns of actions that produce difficulties and conflict. Together, the sociologist and clients may isolate problems through careful description and analysis of the social situationthis is social diagnosis. The next step is to involve the clients in the application of social science knowledge and thinking to the diagnosed problem. The real concern is whether the knowledge is available and whether it is applicable to the situation diagnosed. Once understanding is achieved, prescription is possible if appropriate knowledge and techniques are available.

A further role of the clinical sociologist is to outline the possible alternatives, their meanings and consequences, and bring to the awareness of the clients the feelings, attitudes, opinions and willingness to participate in the resolution process. At times, it is useful to help the participants, say in a family, to make commitments to working with the agreed-upon alternative. In many cases, after a family has agreed to, for example, establish a budget to guide them in the management of their income, key members will violate such agreements. The commitment adds a dimension to the agreement.

The role of the client is to be open and honest, allowing feelings to be exposed. Occasionally risks are involved. But it is essential that honest feelings, perspectives and views are shared in the process of diagnosis and treatment.

\section{THE CHURCH AS A SETTING FOR SOCIOTHERAPY}

Family sociologists as Sociotherapists ${ }^{2}$ have a special opportunity to offer clinical services to families as social units and to individual members of the family. An approach the author has used, which has proved successful in two cities, is to use the church as a frame of reference and point of contact with families.

The first step in the process of offering clinical services to families in the context of the church is to collect the names and addresses of all churches and their pastors. It is often advantageous to establish a relationship with a pastor who can assist in making contacts with other pastors and churches. If a popular pastor allows the sociotherapist to offer clinical services to his congregation, a basis is established for introducing the clinical services to other pastors and churches.

Once the names and addresses are obtained, and a demonstration of the services performed, a letter is sent to each pastor offering the services to his congregation and identifying the topics, process and benefits to their members as families and to their churches as families. A schedule can be established when the pastor makes contact for the services. A visit to each church prior to and especially after the contact for services allows the clinician to be introduced to the members and get a sense of the setting of the church.

The facilities of the church provide a comfortable place for the clinician and family members. Moreover, the church is an appropriate context for diagnosis and treatment of individual and family problems. A significant number of those living in the city are churchgoers, and they view the church as a legitimate intervention mechanism. In many respects, the role and functions of the church are established as a therapeutic unit in the environment of the community; the services of the sociotherapist are an added dimension.

Clients tend to be more open and honest in the setting of the church and seem more willing to express feelings and take risks. Commitments made within the facilities of the church are 
more likely to be kept. Most urban clients feel more hopeful dealing with their problems in the setting of the church. The process of clinical intervention for growth, development and positive functioning is associated, for the clients, with the growth, development and success they experience as members of the church.

The role of the pastor is that of a middleman. Although he may not know the details of the problem(s), he stays in touch with each family and consults with the clinician occasionally regarding the situation of each family. The pastor is usually the person with whom the family or individual makes initial contact. In many cases, it is simple to obtain the approval of the pastor to seek (Sociotherapy ${ }^{3}$ ) clinical or counseling services or to let the pastor know he/she is willing to grow and overcome individual or family problems. It is important that the pastor stay in touch with the individual and families, and inform the clinician of the needs and concerns of the clients. The relationship among the pastor, the clinician and the family members is a significant factor in the process of diagnosis and treatment.

The series of Family Life Seminars and Workshops that are offered to churches under this approach include an initial seminar on Family Schemes (strategies) of coping, which establishes the foundation for the discussion of Communications in Family Life, Openness and Honesty in Family Life, Sexual Interaction and Sexual Difficulties in Family Life, Budgeting in Family Life, The Father's Role in Family Life and an exercise in Family Checkup.

After the three days of seminars and at the end of each seminar, the participants are encouraged to ask questions either verbally or in writing. The pastor or his wife is usually the first to take the risk of asking questions. If the risk is too great for some, they are encouraged to place their questions in a question box that is made available at the start of the Family Life Seminars and Workshops. It is during these sessions that individuals gain added insights into their own familial and/or individual situations. If the questions require detailed analysis and interpretation, or if an analysis or diagnosis cannot be adequately made during this question and answer period, the individuals are asked to make personal contact with the clinician. Ways of making contact are issued to all participants and left with the pastor. When the individual or pastor calls, a meeting is established with the client and the session begins at the church in the pastor's study or in a room adequately prepared and designated for the clinical session.

There are several advantages to the use of the church as the context for therapeutic intervention in family life. First, the clinician is known to the church body and especially to the pastor who approves the sessions. Most urban churchgoers have a significant degree of confidence in their pastors. Second, the church setting is familiar to the members, and the religious climate makes more believable the diagnosis and prognosis. Members may then be more likely to believe the diagnosis and prescription suggested to them by the clinician. Third, it frees the pastor to do spiritual work, and fourth, it reinforces the importance of the college from which the professional received his/her training, the family, and the church, as related institutions vital to the growth and development of the community.

A significant number of church members in the urban community cannot afford to pay for the counseling-clinical sessions. However, most church members contribute to the tithe and offerings of the church. Many churches pay for the services rendered to its members. Some churches establish an account for the poor from which such payments are made.

The clinician-counselor would submit the number of hours each week to the pastor, signed by the client and the therapist. At the end of the month, the church board, the pastor, or the executive committee of the church would authorize such payments.

The fees are usually half the regular fees to the general public because of the use of the church. Depending on the number of people who cannot pay for services and the number seeking clinical-counseling assistance, this responsibility of the church will not be viewed as a burden but as real service to needy members of the congregation.

As families and individual members are helped, the church gets stronger and the pastor is held in higher esteem for allowing such services as part of the total mission of the church. 
Occasionally, the sociotherapist might speak to the entire church on "Men's Day" or "Women's Day" on topics such as"Child Development in the Home," or "The Mother's Role in the Home," etc. At times an entire sensitivity session might be conducted to bring the church members closer together. There are large numbers of church members who do not really know each other and have no mechanism, except an occasional picnic, to get to know each other. These clinical sessions are viewed as having a purifying and cleansing effect on the church collectively if conducted correctly, and growth benefits to the individual as he/she participates. Most pastors believe that the sessions enhance the spiritual life of the church.

\section{CONCLUSIONS}

The question that all clinical sociologists must settle for clinical purposes is: To what extent is human behavior generated by the social context in which it occurs, and to what extent do individuals create a reality, through the process of interpretation, that determines their behavior irrespective of the social situation in which they find themselves? Therefore, instead of the question of "What use is a sociologist?" or "What does a sociologist do?" or even "What does a sociologist produce?", the question should be, "Of what use is sociology?", and "What can sociology do?", and "What does sociology produce?" The fact of the matter is that other professions use the knowledge created by sociologists. Social workers, criminologists, economists, historians, psychologists, psychiatrists, family counselors and others have all depended on clinical research information produced by the discipline of sociology. To give the impression that the value of the content and context of the discipline is diminished because the value of sociologists is questioned is to distort the issue. The important concern of those of us who want to develop, establish and practice clinical sociology as an alternative is to raise the question: What is the knowledge being created by sociology and to what end(s) should it be used? Clinical sociology is an alternative; and a viable one; it is not, however, the essence of the discipline, nor is it the salvation of sociology. Those of us who promote this alternative must understand this and not lead students to believe that in order to be useful sociologists, they must become clinical sociologists. In fact, it may be an error to promote sociological knowledge over social science knowledge because, of all the social science disciplines, sociology, by definition, focuses most closely on human behavior in group life, and human creation and participation in social situations. The social sciences are a single science that has the behavior of mankind as its subject matter. Consequently, any one discipline will always be one-sided as long as it views man as standing alone. The definition of clinical sociology could very well be the application of social science knowledge and thinking to the problems of individuals, families, groups, organizations, industry and communities. No discipline in the social sciences can adequately address the problems faced by these various concerns based on its knowledge alone. Consequently, the knowledge produced by the social sciences in general might be used by all social clinicians in the practice of diagnosis and treatment.

In attempting to organize and establish clinical sociology we must not develop the posture of independence that other clinicians assume even when the knowledge they apply is sociological. For a variety of reasons, during the development of the discipline of sociology there has been some resistance to establishing an applied branch of the discipline for clinical practice. Psychologists and social workers applied sociological knowledge and thinking to social and behavioral problems. Nonetheless, sociologists have occupied roles as clinicians offering sociological insights and analysis as consultants, social analysts, etc., but not as clinical sociologists, or sociotherapists.

Research activity in sociology has created a vast amount of knowledge that is today being used by other social and behavioral scientists as clinicians. To add to the list of clinicians the clinical sociologist assures the full and complete form of application to the troublesome spots, conflicts and crises of individuals, groups, families, organizations, communities and industries, for the purpose of maximum functioning.

The interest and recurring focus of clinical sociology is evident not merely because there is a need for the practical application 
of sociological knowledge and the need for additional and/or new job outlets for sociologists, but also because other clinicians do not seem to adequately understand the social nature of individuals, groups, organizations and their problems. Moreover, most clinicians have come to accept the inadequacy of applying purely psychological and psychiatric knowledge to problems lodged primarily in a social context.

\section{NOTES}

1. Clinical sociology is applied sociological knowledge and thinking for purposes of investigation, diagnosis of problems, and suggestion of strategies for coping with such problems, and achieving change in social situations and interactional patterns.

2. A sociotherapist is one trained in sociology who is capable of making diagnosis and formal assessments of interactional patterns and socia situations to arrive at clinical judgments, and to offer techniques, schemes, and strategies for intervention to facilitate change.

3. Sociotherapy is a process aimed at achieving constructive social and behavioral changes in social situations and in the interactional patterns among individuals, group, organizations and communities.

\section{REFERENCES}

Wirth, Louis

1931 "Clinical sociology." American Journal of Sociology 37:49-66.

\section{BOOK REVIEW}

William Petersen, Malthus. Cambridge, Mass.: Harvard University Press, 1979, 302pp.

Petersen's new book on Thomas Robert Malthus (1766-1834) attempts to present Malthus's work, the historical setting that influenced him, and many of the different responses to his writings. The historical framework that Petersen presents is valuable in understanding how Malthus and his work fit into the development of social thought, economics, demography, political movements, and laws.

The opening chapter places Malthus in the time of the French and Industrial Revolutions. Science, technology and religious beliefs were undergoing a metamorphosis. Scholarly concern was moving from moral philosophy to political economy. Malthus, who taught in a mercantilist college sponsored by the East India Company, and who later became the first professor of political economy, was understandably caught up in these changes.

Having presented the historical framework, Petersen proceeds to a portrait of Malthus and his work. No one could hate the Malthus Petersen portrays: a bird watcher, chess player, hunter, and humanitarian. This should give the reader a hint of Petersen's point of view; he defends Malthus in most respects, acknowledging only minor shiortcomings in Malthus's work, most of which were corrected (at least from Petersen's perspective) in later works and editions.

The defense begins immediately in the second chapter, in which Petersen points out that Malthus was a professor, not just a reverend, as many critics have presented him. Petersen paints Malthus as a religious moderate, attacked by "fanatics from both extremes." Malthus is said to have been maligned by Marx, Cobbett, Godwin, Condorcet, and many others, all of whom were guilty of factual errors concerning the work and thought of Malthus. While Petersen does list the critics' errors, he does not show the effect of the errors on the substance of their arguments. 